\title{
Immune Reconstitution Inflammatory Syndrome in HIV-Infected Immigrants
}

\author{
María Pérez-Rueda, ${ }^{1}$ Michele Hernández-Cabrera, ${ }^{2,3}$ Adela Francés-Urmeneta, ${ }^{3}$ Alfonso Angel-Moreno, ${ }^{4}$ Elena Pisos-Álamo, ${ }^{2,3}$ \\ Nieves Jaén-Sánchez, ${ }^{2,3}$ Cristina Carranza-Rodríguez, ${ }^{2,3}$ and Jose-Luis Pérez-Arellano ${ }^{2,3 *}$ \\ ${ }^{1}$ Internal Medicine, Hospital San Roque Maspalomas (HSRM), Gran Canaria, Spain; ${ }^{2}$ Department of Medical and Surgical Sciences, University of \\ Las Palmas, Las Palmas, Spain; ${ }^{3}$ Unit of Infectious Diseases and Tropical Medicine, Hospital Universitario Insular de Gran Canaria (HUIGC), \\ Las Palmas, Spain; ${ }^{4}$ Internal Medicine, Puerta de Hierro Hospital, Madrid, Spain
}

\begin{abstract}
Immune reconstitution inflammatory syndrome (IRIS) includes a group of potentially serious inflammatory processes that may be present in HIV-infected patients after initiating highly active antiretroviral therapy (HAART). Paradoxical IRIS is a worsening of symptoms, after an overwhelming response to a previously diagnosed opportunistic infection (OI); unmasking IRIS reveals a previously occult OI. The main objective of the study was to describe the epidemiological, clinical, and outcome data of HIV-infected immigrants, stratified according to high- or low-income countries of origin, who developed IRIS and to compare them with native-born Spanish patients. This retrospective study reviewed all patients with HIV infection admitted to the Unit of Infectious Diseases and Tropical Medicine between 1998 and 2014. IRIS was identified in 25/138 (18\%) immigrant patients and 24/473 (5\%) native-born Spanish patients infected with HIV. Most cases, 19/25 (76\%), were of unmasking IRIS. The time elapsed between initiation of HAART and development of IRIS was significantly longer in patients with unmasking versus paradoxical IRIS. Ols, in particular due to mycobacteria, were the most frequently involved processes. Twenty percent of patients died. The comparison of immigrant and native-born patients found significant differences for both IRIS type (higher incidence of paradoxical forms among immigrants) and for the absence of malignancies in native-born patients. No significant differences were found when the data of immigrants from low- and high-income countries were compared.
\end{abstract}

\section{INTRODUCTION}

The immune system is the main mechanism of host defense against infections and tumors. Nevertheless, a strong immune response can sometimes worsen the clinical expression and outcome of the disease. This situation is described generally as immune reconstitution inflammatory syndrome (IRIS) and often occurs in HIV-infected patients after initiation of highly active antiretroviral therapy (HAART). ${ }^{1}$ It can also present in other forms of immunosuppression ${ }^{2-5}$ in patients thought to be immunocompetent who start receiving treatment of certain infections (such as leprosy or tuberculosis) ${ }^{6-8}$ and even during physiological conditions such as pregnancy. ${ }^{9}$

The generally accepted diagnostic criteria for IRIS are as follows ${ }^{1,10,11}: 1$ ) there is a temporal relationship with initiation of HAART and a setting of rapid reduction in plasma HIV viral load (VL) (> 2 log copies $/ \mathrm{mL})^{10}$ and a rapid increase in $\mathrm{CD4}{ }^{+}$ cell count; 2) either clinical and/or radiological deterioration (usually with atypical characteristics) of an ongoing opportunistic process (paradoxical IRIS), or the onset of a new, previously undiagnosed opportunistic infection (OI) (unmasking IRIS); and 3) other explanations (treatment failure, drug interactions, or drug toxicity, autoimmune disease, a new OI unrelated to IRIS) have been completely ruled out.

The IRIS incidence rate ${ }^{12}$ and the interval between initiation of HAART and the presentation of the infections involved vary significantly in different series. ${ }^{13-16}$ Younger age, male sex, low $\mathrm{CD}^{+}$cell counts, high VL and certain HLA haplotypes or polymorphisms in some cytokine genes ${ }^{17,18}$ have all been considered potential risk factors for IRIS. The risk factors can

* Address correspondence to José-Luis Pérez-Arellano, Department of Medical and Surgical Sciences, University of Las Palmas, Avda Maritima del Sur, Las Palmas 35080, Spain and Unit of Infectious Diseases and Tropical Medicine, Hospital Universitario Insular de Gran Canaria (HUIGC), Avda Marítima del Sur, Las Palmas 35080, Spain. E-mail: jlperez@dcmq.ulpgc.es also vary depending on the region of origin of the patient, although this issue has not been extensively studied. ${ }^{19-21}$

The main objective of this study was to perform a retrospective analysis of all cases of HIV-infected immigrants who developed IRIS and were managed at our center between 1998 and 2014. Secondary objectives were to compare these data with those collected from the native-born population and to study potential effects related to the socioeconomic status (high-income versus low-income) of their countries of origin.

\section{MATERIALS AND METHODS}

Setting, study population, and duration of the study. This was a retrospective study, including a study population of all HIV-infected patients who developed IRIS and were managed in the Unit of Infectious Diseases and Tropical Medicine at the Hospital Universitario Insular de Gran Canaria, Las Palmas, Spain, between January 1, 1998 and December 31, 2014.

Definitions. Immigrant was defined as any person arriving in a country or region other than their place of origin and settling there temporarily or permanently. Using the definitions and criteria of the World Bank classification of countries, gross national income (GNI) per capita [defined as gross domestic product divided by the number of inhabitants of a country] was as follows: low-income countries have a dollar GNI per capita of $\$ 1,035$ or less, lower-middle-income countries between $\$ 1,036$ and $\$ 4,085$, upper-middle-income countries between $\$ 4,086$ and $\$ 12,615$, and high-income countries $\$ 12,616$ or more.

Inclusion and exclusion criteria. All medical records of HIV-infected patients managed at our center during this period were reviewed and only those with a diagnosis or suspected diagnosis of IRIS were included in the study. Excluded from the study were patients whose nationality was not recorded or for whom the necessary information (Figure 1) was not available.

Variables. The study data were collected from the patient's medical records and sorted into three groups: 


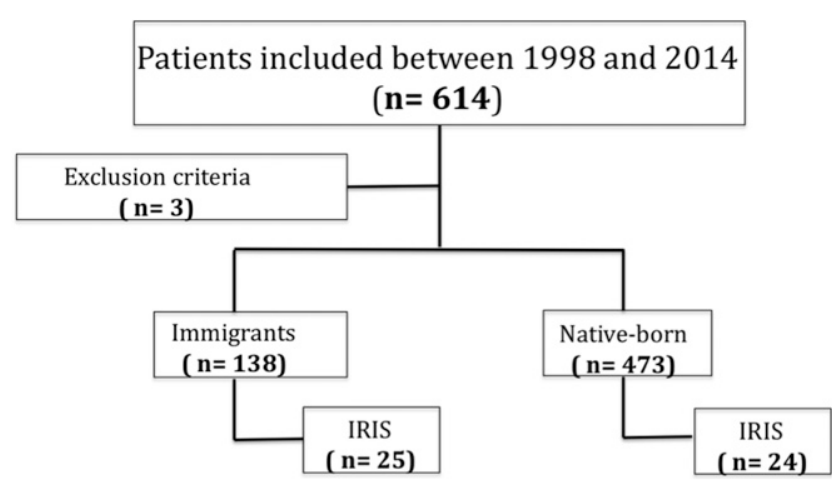

FIGURE 1. Retrospective review of HIV-infected patients with IRIS between 1998 and 2014, University Hospital of Gran Canaria, Las Palmas, Spain. IRIS = immune reconstitution inflammatory syndrome.

- Epidemiological variables included age, sex, race, country of origin (low-income, high-income), immigrant.

- Clinical variables included 1) HIV-related variables: mode of HIV transmission (unknown, heterosexual, homosexual, intravenous drug use), date of diagnosis, date of HAART, HAART schedule; 2) IRIS-related variables: date of diagnosis, IRIS type (paradoxical, unmasking), etiologic classification (Ols, other infections, autoimmune or tumor), causative agent (bacterial, mycobacteria, fungal, viral, parasitic); 3) OI-related variables: date of diagnosis, treatment or prophylaxis at start of HAART; and 4) Immune and virological variables: analytical values at commencement of HAART (CD4 ${ }^{+}$cell count, CD4/CD8 ratio, VL) and analytical values at the time of IRIS diagnosis (CD4+ count, CD4/CD8 ratio, VL).

- Other variables were 1) treatment variables: maintained HAART, administration of nonsteroidal anti-inflammatory drugs, steroids or others, hospitalization time, intensive care unit (ICU) admission, and IRIS as cause of death; and 2) interval variables: HAART-IRIS interval (time elapsed between initiation of HAART and development of IRIS symptoms), HIVIRIS interval (time elapsed between diagnosis of HIV infection and development of IRIS symptoms), HIV-HAART interval (time elapsed between diagnosis of HIV infection and initiation of HAART), and OI-IRIS interval (time elapsed between diagnosis of OI and development of IRIS symptoms).

Statistical analysis. Qualitative variables were expressed as frequency distributions. Quantitative variables were expressed as mean and standard deviation (SD) if normally distributed, and as median and interquartile range (IQR) if not normally distributed. The $x^{2}$ test was used to analyze associations between qualitative variables. For comparisons, the Student's $t$ test was used for normally distributed variables, and the Mann-Whitney test for variables that were not normally distributed. Data distributions compared with theoretical models were verified and the assumption of homogeneity of variance (ANOVA) was tested in all cases. Results were considered statistically significant at $P<0.05$.

Ethical considerations. This study observed the principles of the Declaration of Helsinki. Data confidentiality was protected according to the Data Protection Act, Law 41/2002, of November 14 , regulating the autonomy of patients and their rights and obligations in relation to clinical information and documentation.

\section{RESULTS}

A total of 49 patients with IRIS were analyzed. Figure 2 shows the temporal evolution of those IRIS patients managed at our center between 1998 and 2014. The mean age was 37 (SD 10) years, 71\% (35/49) were male. Modes of HIV transmission were unknown 29\% (14/49), heterosexual 25\% (12/49), male-to-male sexual contact $22 \%(11 / 49)$, bisexual $2 \%$ (1/49), and intravenous drug users (IDUs) 22\% (11/49). IRIS type was unmasking in 59\% (29/49) of cases. Seventy-six percent (37/49) of cases were classified as Ols, $16 \%(8 / 49)$ as non-Ols, and 6\% (3/49) were neoplastic diseases; there were no cases of autoimmune disease. At initiation of HAART, patients had mean CD4 T cells of 68 (SD 69) cells/ $\mu \mathrm{L}$ and mean log10 VL values were 5.35 (SD 0.9) copies $/ \mathrm{mL}$. At the time of the IRIS diagnosis, mean CD4 cell count was 224 (SD 192) cells/uL and log10 VL was 2.73 (SD 0.8).

IRIS was identified in $18 \%(25 / 138)$ of immigrants and $5 \%$ (24/473) of native-born Spanish HIV-infected patients.

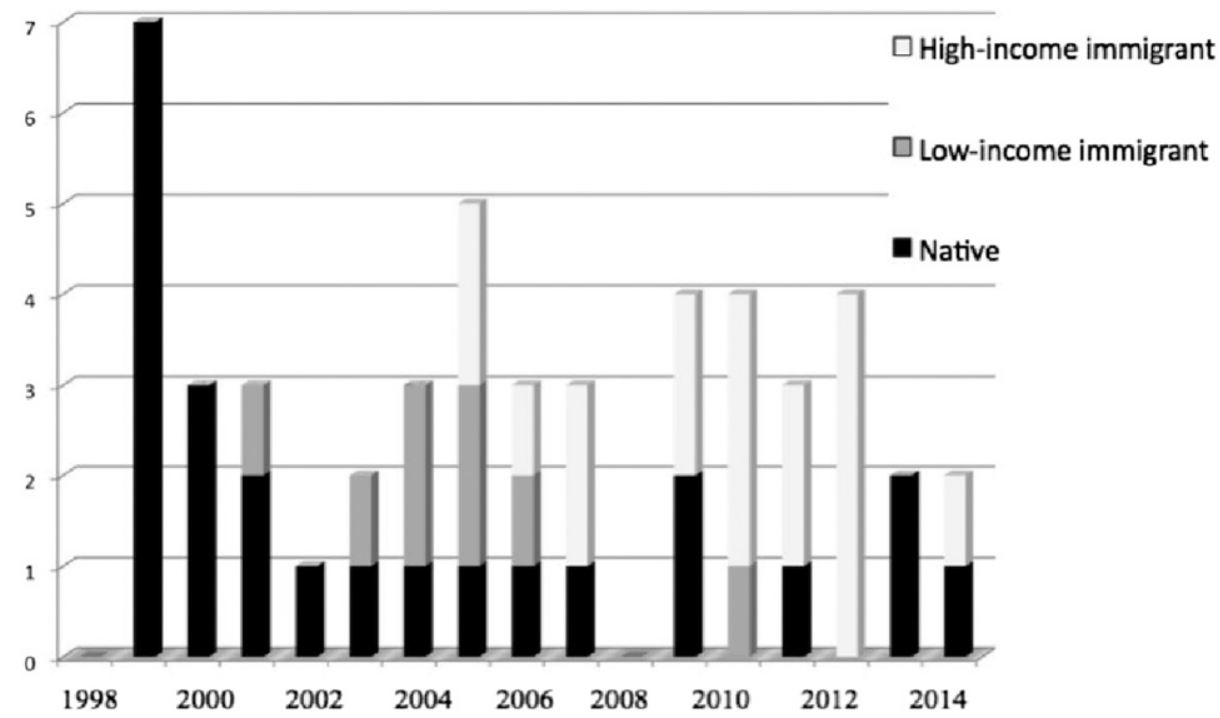

FIGURE 2. Temporal evolution of the number of IRIS patients. IRIS = immune reconstitution inflammatory syndrome. 
A total of $25 \mathrm{HIV}$-infected immigrants who developed IRIS were analyzed: mean age was 39 (SD 10) years, 64\% (16/25) were male; HIV infection was sexually transmitted in $72 \%(18 / 25)$ (same proportions of heterosexuals and homosexuals), $4 \%$ $(1 / 25)$ were IDUs, whereas the mode of transmission was unknown in the rest of cases. Fifty-six percent (14/25) were Caucasian, 36\% (9/25) were Black, 4\% (1/25) Indian, and $4 \%(1 / 25)$ Berber. Figure 3 shows the countries of origin of the immigrants: $32 \%(8 / 25)$ of immigrants came from lowincome countries.

With respect to IRIS type, 76\% (19/25) of cases were unmasking. With regard to etiology, 64\% (16/25) were Ols, $24 \%(6 / 25)$ were nonOls, and $12 \%(3 / 25)$ were neoplastic diseases (one hemophagocytic syndrome, one plasmablastic lymphoma, and one myeloma). The etiologic agents involved were mycobacteria 40\% (10/25) (nine Mycobacterium tuberculosis and one Mycobacterium avium intracellulare), followed by $24 \%(6 / 25)$ bacteria (three Streptococcus pneumoniae, two Escherichia coli, and one methicillin-sensitive Staphylococcus aureus), 20\% (5/25) viruses (four CMV and one HHV8), 4\% (1/25) parasites (1 Toxoplasma gondii), and there were no fungi. Of the six patients previously diagnosed with Ols, three were treated for tuberculosis, two were under treatment of tuberculosis at initiation of HAART, and one was a T. gondii infection, also under treatment.

At the commencement of HAART, patients had a mean CD4 T-cell count of 33 (SD 86) cells/ $\mu \mathrm{L}$, mean CD4/CD8 ratio of 0.2 (SD 0.2), and $80 \%$ of patients had a VL above 100,000 copies $/ \mathrm{mL}$. At the time of IRIS diagnosis, the median CD4 ${ }^{+}$count was 175 (IQR 269) cells/ $\mu \mathrm{L}$; mean CD4/CD8 ratio was 0.3 (SD 0.2), and $80 \%$ had a VL below 1,000 copies $/ \mathrm{mL}$.

The mean time interval between HIV diagnosis and HAART initiation was 898 days, and between HAART initiation and onset of IRIS, 31 days (range 5-127 days). In patients with Ols, the mean time between OI diagnosis and onset of IRIS was 22 days. The mean time between arrival in Spain and development of IRIS was 8 years for immigrants from low-income countries and 3.4 years for those from high-income countries.

In $36 \%(9 / 25)$ of cases, the HAART regimen included protease inhibitors (PIs). The other cases consisted of two nucleoside/nucleotide reverse transcriptase inhibitors and one non-nucleoside reverse transcriptase inhibitor. Eighty percent (20/25) of patients remained on HAART after the IRIS diagnosis. Adjunctive corticosteroid therapy was used in $64 \%$ $(16 / 25)$ of cases.

Mean (SD) hospitalization was 28 (SD 19) days. One patient required admission to the ICU. Five patients died while admitted; four as a result of IRIS. The mean time from diagnosis of IRIS until death was 20 days.

Concerning potential relationships between gender and other variables, significant differences were observed for the mode of HIV acquisition (heterosexual transmission in $66.7 \%$ of women; homosexual transmission in $56.2 \%$ of men; $P=0.02$ ) and for nadir CD4 cell count ( 88 cells/ $\mu \mathrm{L}$ for men, 25 cells/ $\mu \mathrm{L}$ for women; $P=0.011)$. Race and mortality were not significantly associated with etiologic agent or other analyzed variables.

Paradoxical IRIS developed sooner than the unmasking type after initiation of HAART (30 versus 56 days; $P=0.048$ ). Hospitalization varied according to etiology: OI (34 days), nonOI (14 days), and tumor (20 days), $P=0.026$. The time between diagnosis of the OI and onset of IRIS was significantly longer for parasitic infections than for mycobacteria (76 versus 11 days, $P=0.003$ ).

Higher CD4 nadirs were associated with longer time intervals between HIV diagnosis and onset of IRIS (paradoxical or unmasking) $(P=0.038)$ and between initiation of HAART and diagnosis of IRIS $(P=0.039)$. The patients with the longest stays in hospital were those with longer times between HIV diagnosis and onset of IRIS $(P=0.023)$ and those with shorter times between diagnosis of $\mathrm{OI}$ and onset of IRIS $(P=0.010)$.

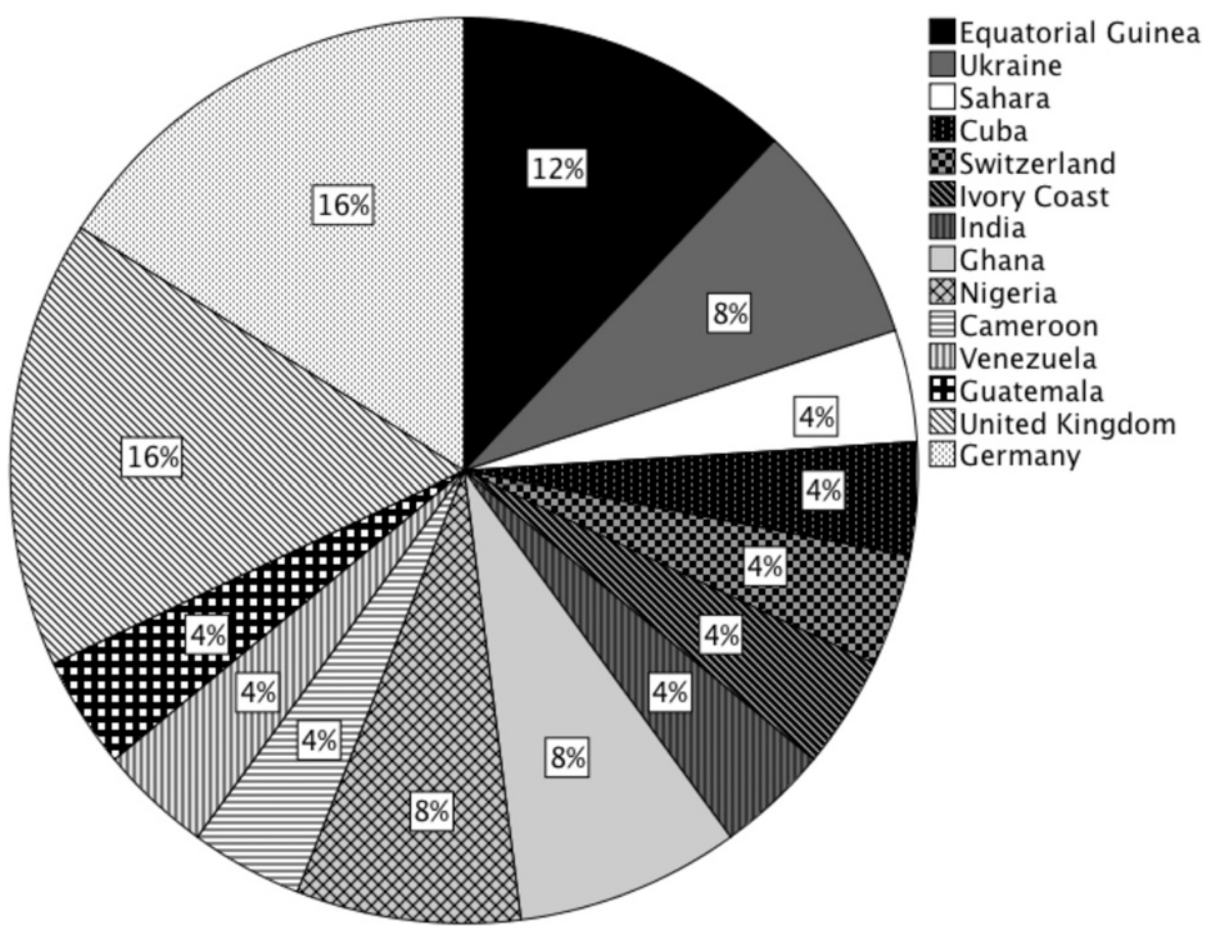

FIGURE 3. Country of origin of IRIS patients. IRIS = immune reconstitution inflammatory syndrome. 
Tables 1 and 2 compare the demographic, clinical, and analytic variables of immigrant and native-born Spanish patients with IRIS. Statistically significant differences were found for mode of transmission, race, and IRIS type.

For the comparison of high-income versus low-income countries of origin, only two variables showed statistically significant differences: age and race. Patients from highincome countries were older (42 versus 33 years, $P=0.017$ ) and included all Caucasians in the study $(P=0.001)$. There were no statistically significant differences between nativeborn patients and immigrants for variables associated with immunovirologic status or time intervals, regardless of country of origin.

\section{DISCUSSION}

IRIS has been known for years as a serious, potentially lethal complication associated with the initiation of HAART, with higher prevalence in patients with more intense immunosuppression (very low CD4 cell counts and high VL). The latter finding should support early initiation of HAART. Although IRIS is potentially fatal, it can be reversed. ${ }^{22-25}$

The incidence of IRIS is highly dependent on the population involved. It ranges between $3 \%$ and $54 \%{ }^{26,27}$ and varies not only with degree of immune-suppression but also with the prevalence of Ols. The consequences would be expected to be more severe in developing countries, where the two often coexist. $^{28,29}$ Indeed, the incidence of IRIS in our immigrant patients was higher than in those who were native-born: $18 \%$ (25/138) versus $5 \%$ (24/473), respectively, although more frequent among immigrants from high-income countries, which appears somewhat contradictory. A possible explanation for this finding is the fact that we used the World Bank classification of countries, according to which Guatemala and Equatorial Guinea, with epidemiological profiles similar to those of developing countries, were included among the highincome countries (GNI per capita above \$4,086). However, it should also be noticed that CD4 cell counts at the time of diagnosis were very low in both cases.

In our hospital, IRIS was found to be more frequent among immigrants who came from European rather than nonEuropean countries. One possible reason is the large number of European tourists who visit Gran Canaria, which is a common tourist destination because of its proximity to Europe and good climate. Homosexual tourism is also a very important factor. In addition, because of its proximity to Africa, Gran Canaria has been one of the major areas associated with the arrival of undocumented immigrants on pateras (small boats) trying to reach European territory, although there has been a decrease in the influx of such immigrants since the beginning of the twenty-first century. Our study data reflect this phenomenon, with a proportional decrease in the number of immigrants arriving from African countries since 2007. The opposite situation can be observed for those from highincome countries, which mainly includes a type of tourist arriving for long-term, low-cost stays. Cases among Spanish

TABLE 1

Demographic, clinical, and management outcome of IRIS patients

\begin{tabular}{|c|c|c|c|c|}
\hline & Immigrants $N(\%)$ & Natives $N(\%)$ & OR $(95 \% \mathrm{Cl})$ & $P$ \\
\hline Age & $39(10)^{\star}$ & $36(10)^{\star}$ & - & 0.241 \\
\hline Sex (men) & $16(64.0)$ & 19 (79.2) & $0.47(0.13-1.68)$ & 0.240 \\
\hline \multicolumn{5}{|l|}{ Way of HIV transmission } \\
\hline Heterosexual & $9(36.0)$ & $3(12.5)$ & 1 & 0.003 \\
\hline Male-to-male sexual contact & $9(36.0)$ & $2(8.3)$ & $1.50(0.20-11.24)$ & - \\
\hline Intravenous drug use & $1(4.0)$ & $10(41.7)$ & $0.03(0.00-0.38)$ & - \\
\hline Unknown & $6(24.0)$ & $9(37.5)$ & $4(0.74-21.49)$ & - \\
\hline \multicolumn{5}{|l|}{ Race } \\
\hline Caucasian & $14(56.0)$ & $24(100)$ & - & 0.003 \\
\hline Black & $9(36.0)$ & $0(0)$ & - & - \\
\hline Indian & $1(4.0)$ & $0(0)$ & - & - \\
\hline Berber & $1(4.0)$ & $0(0)$ & - & - \\
\hline IRIS type & & & $4.43(1.30-15.09)$ & 0.015 \\
\hline Paradoxical & $6(24.0)$ & $14(58.3)$ & & \\
\hline Unmasked & 19 (76.0) & $10(41.7)$ & & \\
\hline \multicolumn{5}{|l|}{ According to etiology } \\
\hline Opportunistic infection & $16(66.7)$ & $22(91.7)$ & 1 & 0.084 \\
\hline Other infections & $6(25.0)$ & $2(8.3)$ & $3.94(0.70-22.15)$ & - \\
\hline Autoimmune & $0(0)$ & $0(0)$ & - & - \\
\hline Tumor & $3(12.5)$ & $0(0)$ & $0.43(0.29-0.63)$ & - \\
\hline \multicolumn{5}{|l|}{ Causal agent } \\
\hline Bacteria & $6(27.3)$ & $1(4.3)$ & $0.15(0.01-1.49)$ & 0.135 \\
\hline Mycobacteria & $10(45.5)$ & $11(47.8)$ & 1 & - \\
\hline Fungi & $0(0)$ & $3(13.1)$ & - & - \\
\hline Virus & $5(22.7)$ & $6(26.1)$ & $0.92(0.21-3.96)$ & - \\
\hline Parasites & $1(4.5)$ & $2(8.7)$ & $0.55(0.04-7.03)$ & - \\
\hline HAART schedule (including PI) & $9(36.0)$ & $4(16.7)$ & $0.36(0.09-1.37)$ & 0.125 \\
\hline Remained at HAART & $20(80.0)$ & $15(62.5)$ & $1.67(0.38-7.29)$ & 0.495 \\
\hline Corticosteroid treatment & $16(64.0)$ & $12(48.0)$ & $1.78(0.57-5.58)$ & 0.322 \\
\hline ICU admission & $1(4.0)$ & $1(4.2)$ & $0.96(0.06-16.24)$ & 0.976 \\
\hline \multicolumn{5}{|l|}{ Mortality } \\
\hline Due to IRIS & $4(16.0)$ & $2(8.3)$ & $0.50(0.02-12.89)$ & 0.715 \\
\hline Other & $1(4.0)$ & $1(4.2)$ & - & - \\
\hline
\end{tabular}

* Data expressed as mean and standard deviation (SD)
* 
TABLE 2

Laboratory data of IRIS patients

\begin{tabular}{|c|c|c|c|c|}
\hline & & Immigrants $N(\%)$ & Natives $N(\%)$ & $P$ \\
\hline \multirow[t]{2}{*}{ At the start of HAART } & $\begin{array}{c}\mathrm{CD}_{4}{ }^{*} \\
\mathrm{CD}_{4} / \mathrm{CD}_{8} \dagger\end{array}$ & $\begin{array}{c}65(69) \\
0.16(0.18)\end{array}$ & $\begin{array}{c}71(70) \\
0.13(0.15)\end{array}$ & $\begin{array}{l}0.805 \\
0.764\end{array}$ \\
\hline & Log VL† & $5.42(1.06)$ & $5.24(0.66)$ & 0.589 \\
\hline \multirow{3}{*}{ At IRIS diagnosis } & $\mathrm{CD}_{4}{ }^{*}$ & $229(216)$ & 215 (155) & 0.838 \\
\hline & $\mathrm{CD}_{4} / \mathrm{CD}_{8} \dagger$ & $0.26(0.25)$ & $0.42(0.42)$ & 0.414 \\
\hline & Log VL† & $2.61(0.57)$ & $2.88(1.16)$ & 0.487 \\
\hline
\end{tabular}

HAART = highly active antiretroviral therapy; IRIS = immune reconstitution inflammatory syndrome; VL = viral load.

* Data expressed as median and interquartile range (IQR).

† Data expressed as mean and standard deviation (SD).

patients have also declined over the years, which can be explained as because of the reduction in the use of intravenous drugs (an important mode of HIV transmission in our study) together with better monitoring of patients and better understanding of IRIS.

IRIS generally manifests within 12 weeks of starting HAART. In our study, 13 cases presented earlier and 12 cases more than 3 months after starting HAART. This period was longer in the case of unmasking IRIS (56 versus 30 days) and in cases caused by parasites.

The characteristics of some patients (intravenous drug users or illegal immigrants) made it difficult to link them to care, which often led to delays in HAART initiation (of up to 2 years). As a result, such patients were more heavily immunosuppressed and at higher risk of developing IRIS.

Differences between low- and high-income countries were associated with clinical features rather than IRIS characteristics, laboratory data, or variables related to treatment.

The proportion of men with IRIS in our study was twice that of women, although women exhibited lower nadir CD4s. Male sex as an independent risk factor for developing IRIS has been reported previously. ${ }^{30}$

The most common IRIS-related Ols worldwide are mycobacteria (mainly $M$. tuberculosis and $M$. avium-intracellulare complex) and Cryptococcus neoformans, although many other microorganisms may be involved. ${ }^{15,16,31-33}$ In our series, mycobacteria were also the leading cause of Ols, but the second most common agent was CMV. In this connection, TB-IRIS patients had significantly greater early increases in the frequency of tuberculosis-specific polyfunctional IFN- $\gamma(+) / I L-$ $2(+) / T N F-\alpha(+)$ CD4 $^{+}$T-cells on HAART. ${ }^{34}$ Interestingly, Cryptococcus spp. was less frequent and was identified only in Spanish patients. At the start of HAART, two patients were undergoing treatment of tuberculosis and one for T. gondii infection, although none of them were taking prophylaxis against Ols because it was not indicated.

As has been mentioned, IRIS occurred mainly in patients who started HAART with very low CD4 T-cell counts, generally below 350 cells $/ \mu \mathrm{L}$. There were some exceptions, tuberculosis in particular, which has been related to IRIS in patients with higher CD4 cell counts, and even in nonimmunosuppressed patients after starting antituberculosis drugs. ${ }^{17}$ Nevertheless, in our study, no patient with an initial CD4 count above $200 / \mu \mathrm{L}$ had tuberculosis.

Patients were hospitalized for a mean of 28 days. This period was less for those with a shorter interval between diagnosis of OI and IRIS, perhaps because the clinician in those cases had greater diagnostic suspicion or carried out more exhaustive controls, so that treatment began with less possibility of complications. Prevention of IRIS depends to a great extent on an optimal screening for Ols before the patient starts HAART, both to prevent the appearance of the unmasking type and to optimize the timing of HAART initiation in those patients already receiving treatment of an OI. For this reason, some authors have proposed exhaustive screening before initiation of HAART and closely monitoring those patients who initiate it with very low CD4 levels, even if there is a history of infection. ${ }^{35}$ Other preventive measures that have been proposed include ${ }^{36}$ assessing the endemicity of the OI and administering secondary prophylaxis against certain infections regardless of immunological status, treating the $\mathrm{OI}$ and reducing the pathogen burden before initiating HAART, and delaying initiation of HAART in certain Ols bearing a potential risk of worsening under specific treatment (particularly in tuberculosis).

Finally, in relation to mortality, five patients died during admission, four of them as a result of IRIS. Overall mortality, particularly due to IRIS was higher among immigrant patients than native-born ones, $16 \%(4 / 25)$ versus $8 \%(2 / 24)$, and all were from high-income countries. In our study, mortality was not significantly associated with any of the variables collected.

When designing the study, every effort was made to avoid misclassification or selection biases typical of retrospective studies. Because patients were recruited through discharge reports and all had a firm diagnosis of IRIS, cases with less serious clinical/radiological pictures were excluded. However, it should be mentioned that in our Unit, every outpatient with suspected or even mild IRIS was routinely proposed for hospitalization for closer monitoring.

Finally, it should be noticed that the study period was long (16 years), so that many changes in the characteristics of HIV patients may have occurred (i.e., type of treatment or diagnostic methods).

Received September 26, 2016. Accepted for publication July 15, 2017. Published online August 14, 2017.

Acknowledgments: We would like to thank Janet Dawson for her help in revising the English version of the manuscript.

Authors' addresses: María Pérez-Rueda, Internal Medicine, Hospital San Roque Maspalomas (HSRM), Gran Canaria, Spain, E-mail: dra. perezrueda@gmail.com. Michele Hernández-Cabrera, Elena PisosÁlamo, Nieves Jaén-Sánchez, Cristina Carranza-Rodríguez, and Jose-Luis Pérez-Arellano, Department of Medical and Surgical Sciences, University of Las Palmas, Las Palmas, Spain, and Unit of Infectious Diseases and Tropical Medicine, Hospital Universitario Insular de Gran Canaria (HUIGC), Las Palmas, Spain, E-mails: michele_herca@hotmail.com, elenapisos@yahoo.es, nieves. jaensanchez@gmail.com, cristinacarranzarodriguez@gmail.com, and jlperez@dcmq.ulpgc.es. Adela Francés-Urmeneta, Unit of Infectious 
Diseases and Tropical Medicine, Hospital Universitario Insular de Gran Canaria(HUIGC), Las Palmas, Spain, E-mail: adelafrances@telefonica.net. Alfonso Angel-Moreno, Internal Medicine, Puerta de Hierro Hospital, Madrid, Spain, E-mail: alfangel22@hotmail.com.

\section{REFERENCES}

1. French MA, 2009. HIV/AIDS: immune reconstitution inflammatory syndrome: a reappraisal. Clin Infect Dis 48: 101-107.

2. Singh N, Perfect JR, 2007. Immune reconstitution syndrome associated with opportunistic mycosis; risk factors, pathophysiologic basis and approach to management. Lancet Infect Dis 7: 395-401.

3. Cheng VC, Yuen KY, Chan WM, 2000. Immunorestitution disease involving the innate and adaptive response. Clin Infect Dis 30: 882-892.

4. Singh N, et al.; Cryptococcal Collaborative Transplant Study Group, 2005. An immune reconstitution syndrome-like illness associated with Cryptococcus neoformans infection in organ transplant recipients. Clin Infect Dis 40: 1756-1761.

5. Cadena J, Thompson GR 3rd, Ho TT, Medina E, Hughes DW, Patterson TF, 2009. Immune reconstitution inflammatory syndrome after cessation of the tumor necrosis factor alpha blocker adalimumab in cryptococcal pneumonia. Diagn Microbiol Infect Dis 64: 327-330.

6. Cheng VC, Ho PL, Lee RE, 2002. Clinical spectrum of paradoxical deterioration during antituberculosis therapy in non-HIVinfected patients. Eur J Clin Microbiol Infect Dis 21: 803-809.

7. Garcia Vidal C, Rodríguez Fernández S, Martínez Lacasa J, Salavert M, Vidal R, Rodríguez Carballeira M, Garau J, 2005. Paradoxical response to antituberculous therapy in infliximabtreated patients with disseminated tuberculosis. Clin Infect Dis 40: 756-759.

8. Lawn SD, Lockwood DNJ, 2007. Leprosy after starting antiretroviral treatment. BMJ 334: 217-218.

9. Singh N, Perfect JR, 2007. Immune reconstitution syndrome and exacerbation of infections after pregnancy. Clin Infect Dis 45: 1192-1199.

10. Shelburne SA, Hamili RJ, 2003. The immune reconstitution inflammatory syndrome. AIDS Rev 5: 67-69.

11. Shelburne SA, Montes M, Hamill R, 2006. Immune reconstitution inflammatory syndrome: more answers, more questions. $J$ Antimicrob Chemother 57: 167-170.

12. Sungkanuparph S, et al., 2009. Cryptococcalimmune reconstitution inflammatory syndrome after antiretroviral therapy in AIDS patients with cryptococcal meningitis: a prospective multicenter study. Clin Infect Dis 49: 931-934.

13. Haddow LJ, Moosa MY, Mosam A, Moodley P, Parboosing R, Easterbrook PJ, 2012. Incidence, clinical spectrum, risk factors and impact of HIV associated immune reconstitution inflammatory syndrome in South Africa. PLoS One 7: e40623.

14. Jarvis JN, et al., 2014. Determinants of mortality in a combined cohort of 501 patients with HIV-associated Cryptococcal meningitis: implications for improving outcomes. Clin Infect Dis 58: 736-745.

15. Shelburne SA, Visnegarwala F, Darcourt J, Graviss EA, Giordano TP, White AC Jr, Hamill RJ, 2005. Incidence and risk factors for immune reconstitution inflammatory syndrome during highly active antiretroviral therapy. AIDS 19: 399-406.

16. Murdoch DM, Venter WD, Feldman C, Van Rie A, 2008. Incidence and risk factors for the immune reconstitution inflammatory syndrome in HIV patients in South Africa: a prospective study. AIDS 22: 601-610.

17. Geng EH, Deeks SG, 2009. CD4+T cell recovery with antiretroviral therapy more than the sum of the parts. Clin Infect Dis 48: 362-364.

18. Manabe YC, Campbell JD, Sydnor E, Moore RD, 2007. Immune reconstitution inflammatory syndrome: risk factors and treatment implications. J Acquir Immune Defic Syndr 46: 456-462.
19. Ratnam I, Chiu C, Kandala NB, Easterbrook PJ, 2006. Incidence and risk factors for immune reconstitution inflammatory syndrome in an ethnically diverse HIV type 1-infected cohort. Clin Infect Dis 42: 418-427.

20. Lucas SB, 1990. Missing infections in AIDS. Trans $R$ Soc Trop Med Hyg 84 (Suppl 1): 34-38.

21. Lawn SD, 2007. Immune reconstitution disease associated with parasitic infections following initiation of antiretroviral therapy. Curr Opin Infect Dis 20: 482-488.

22. Kwara A, Flanigan TP, Carter EJ, 2005. Highly active antiretroviral therapy (HAART) in adults with tuberculosis: current status. Int $J$ Tuberc Lung Dis 9: 248-257.

23. Lawn ED, Myer L, Bekker LG, Wood R, 2007. Tuberculosisassociated immune reconstitution disease: incidence, risk factors and impact in an antirretroviral treatment service in South Africa. AIDS 21: 335-341.

24. Lee CH, Lui CC, Liu JW, 2007. Immune reconstitution syndrome in a patient with AIDS with paradoxically deteriorating brain tuberculoma. AIDS Patient Care STDS 21: 234-239.

25. Wu SW, Chen CJ, Lin TY, Wang NC, 2008. Acute peritonitis as presentations of tuberculosis-associated immune reconstitution inflammatory syndrome in HIV-infected man. Am J Med Sci 355: 387-389.

26 Fischl M, et al., 2010. IRIS among US Subjects Starting ART in AIDS Clinical Trials Group Study A5202. Program and Abstracts of the 17th Conference on Retroviruses and Opportunistic Infections, February 16-19, 2010, San Francisco, CA. Abstract 791

27. Narendran G, et al., 2013. Paradoxical tuberculosis immune reconstitution inflammatory syndrome (TB-IRIS) in HIV patients with culture confirmed pulmonary tuberculosis in India and the potential role of IL-6 in prediction. PLoS One 8: e63541.

28. Lazarous DG, O'Donnell AE, 2007. Pulmonary infections in the HIV-infected patient in the era of highly active antiretroviral therapy: an update. Curr Infect Dis Rep 9: 228-232.

29. Bonnet MM, Pinoges LL, Varaine FF, Oberhauser BB, O'Brien DD, Kebede YY, Hewison CC, Zachariah RR, Ferradini LL, 2006. Tuberculosis after HAART initiation in HIV-positive patients from five countries with a high tuberculosis burden. AIDS 20: 1275-1279.

30. Orikiriza J, Bakeera-Kitaka S, Musiime V, Mworozi EA, Mugyenyi $\mathrm{P}$, Boulware DR, 2010. The clinical pattern, prevalence, and factors associated with immune reconstitution inflammatory syndrome in Ugandan children. AIDS 24: 2009-2017.

31. Breton G, Duval X, Estellat C, Poaletti X, Bonnet D, Mvondo Mvondo D, Longuet P, Leport C, Vildé JL, 2004. Determinants of immune reconstitution inflammatory syndrome in HIV type-1 infected patients with tuberculosis after initiation of antiretroviral therapy. Clin Infect Dis 39: 1709-1712.

32. Abdool Karim SS, et al., 2010. Timing of initiation of antiretroviral drugs during tuberculosis therapy. N Engl J Med 362: 697-706.

33. Havlir DV, et al., AIDS Clinical Trials Group Study A5221, 2011. Timing of antiretroviral therapy for HIV-1 infection and tuberculosis. N Engl J Med 365: 1482-1491.

34. Ravimohan S, Tamuhla N, Nfanyana K, Steenhoff AP, Letlhogile R, Frank I, MacGregor RR, Gross R, Weissman D, Bisson GP, 2016. Robust reconstitution of tuberculosis-specific polyfunctional CD4+ T-cell responses and rising systemic interleukin 6 in paradoxical tuberculosis-associated immune reconstitution inflammatory syndrome. Clin Infect Dis 62: 795-803.

35. Shankar EM, Vignesh R, Velu V, Murugavel KG, Sekar R, Balakrishnan P, Lloyd CA, Saravanan S, Solomon S, Kumarasamy N, 2008. Does CD4+CD25+foxp3+ cell (Treg) and IL10 profile determine suscep-tibility to immune reconstitution inflammatory syndrome (IRIS) in HIV disease? J Inflamm (Lond) 5: 2.

36. Reyes Corcho A, Bouza Jiménez Y, 2010. Human immunodeficiency virus and AIDS-associated immune reconstitution syndrome. State of the art. Enferm Infecc Microbiol Clin 28: 110-121. 